\title{
A Longitudinal Investigation into the Chinese Language Development of Non-Chinese Speaking Preschoolers in Hong Kong
}

\author{
Shek Kam Tse \\ Faculty of Education, The University of Hong Kong, Hong Kong SAR, China \\ Cheong Yam Leung \\ Faculty of Education, The University of Hong Kong, Hong Kong SAR, China \\ Pik Fong Tsui \\ Faculty of Education, The University of Hong Kong, Hong Kong SAR, China \\ Kit Yee Chan \\ Faculty of Education, The University of Hong Kong, Hong Kong SAR, China \\ Mei Chi Kwok \\ Faculty of Education, The University of Hong Kong, Hong Kong SAR, China
}

\begin{abstract}
Learning Chinese as a second language is challenging for non-Chinese speaking population in Hong Kong. In order to facilitate the Chinese learning of this group of people, understanding their trajectory of Chinese language development is crucial. The present longitudinal study follows 88 non-Chinese speaking preschoolers in 4 time points, from their $\mathrm{K} 1$ to $\mathrm{K3}$, in order to have a grasp of their Chinese language development in three key aspects, namely listening, speaking and reading. Results showed that non-Chinese speaking preschoolers progressed their Chinese language proficiency over time in the three domains, whereas their listening abilities have the best advancement. Though their speaking abilities were the worst at the beginning, they had significant improvement by the end of their K3. The qualitative data provides descriptors of the Chinese language proficiency of non-Chinese speaking preschoolers in different grades. The study's findings serve as a valuable reference for schools regarding school-based curriculum development, learning and teaching materials, approaches and assessments.
\end{abstract}

Index Terms - non-Chinese speaking students, Chinese language development, early childhood education, listening competence, speaking competence, reading competence

\section{INTRODUCTION}

Non-Chinese speaking (NCS) population in Hong Kong constituted 8\% (that is 584,383 people) of Hong Kong total population (Census and Statistics Department, 2017). The young generation of these people are undeniably playing a more important role in future Hong Kong society. These NCS people in Hong Kong generally refer to the non-Chinese Asian ethnic groups, including but not limited to Filipinos, Indians, Nepalese, Pakistanis, Vietnamese, and Bangladesh. Among the ethnic minority people, $14 \%$ of them were born in Hong Kong but only $30.3 \%$ reported that Cantonese was the most commonly used language in their home (Census and Statistics Department, 2017), while Cantonese is the mother-tongue of the majority (89.5\%) of the local population (Census and Statistics Department, 2012).

Though several support services have been launched in primary and secondary schools to enhance NCS school-age children to learn Chinese (Education Bureau, 2017), these students in general are reported to perform at levels below the accepted standards in Chinese language (The Zubin Foundation, 2017) and there is no information of how NCS children progress in their Chinese language learning, especially in their first few years of kindergarten schooling. Being the minority language learners, NCS preschoolers' experience of the local majority language is likely to be restricted (Verhallen \& Schoonen, 1993). Jiang (2004) holds the view that educators should be aware of the distinctive characteristics of the Chinese language, otherwise, analyses may be invalidated if sweeping generalizations are made based upon Western language theories. Therefore, it is crucial to know the Chinese language development of these preschoolers in order to enhance their learning progress.

\section{A. Learning Chinese as a Second Language of NCS Preschoolers in Hong Kong}

As stated by Tabors (2008), young children usually undergo four stages in second language development, they are (i) home language use, (ii) silent period, (iii) telegraphic and formulaic speech, and (iv) productive language. In the first 
stage, young children automatically use their mother tongue to communicate with others in a new language environment (i.e. second language environment). However, most children face obstacles when others cannot understand them. Then, they will enter into the silent period and observe the use of language of other people. They prefer non-verbal communication to verbal communicate. After a period of observation and absorption, children begin to use telegraphic speech (i.e., words or phrases) to communicate with others. In the final stage, children have basic competence in the second language and can use sentences to express themselves. Errors are expected as children try to learn different structures of the new language.

NCS students in Hong Kong are learning Chinese as their second language and the government places their Chinese language proficiency high on its policy agenda (Education Bureau, 2017). Chinese is widely adopted as the medium of instruction in preschools when the government decided to implement the policy of mother-tongue teaching (Curriculum Development Council, 2017). Preschools in Hong Kong offer educational services for three- to six-year-old children. To enhance the Chinese language learning of NCS students, the government encourages "parents of non-Chinese speaking children to arrange for their children to study in kindergartens as early as possible, so their children can be immersed in an authentic Chinese language environment" (Curriculum Development Council, 2017, p. 37).

As a multi-lingual community, Hong Kong has a very rich literacy practice. There are almost 20 language elements that are in use in the daily living of Hong Kong people, including the listening and speaking of Cantonese, Putonghua, and English; reading and writing of modern Chinese and English; reading of classical Chinese; and listening and speaking of minority languages (Tse, 2014). Given the variety of language elements involved, the difficulties of NCS children in learning Chinese as a second language can be imagined.

Second language learners usually transfer some of their first language skills and abilities when acquiring second language. However, this transference ability does not work for ethnic minority preschoolers because their mother tongues (such as English or Thai) mainly follows the phonological principle (Perfetti \& Tan, 1999) in which pronunciation can be reflected through their writing symbols, whereas Chinese is an ideographic language and its writing "does not reflect phonemic representations of sound as alphabetic writing does" (McBride, 2016, p. 527). In a survey completed by over 300 NCS students in Hong Kong (Shum, Gao, Tsung, \& Ki, 2011), most of the students ranked their language competency with English being the best, followed by their mother tongues, and Chinese (reading and writing) as the weakest.

\section{B. Learning of Chinese Language}

Regardless of language involved, words "must now be recognized and matched with spoken words and sounds" (Chall, 1983, p. 41) at the initial stage of literacy development. Chinese is ideographic in origin with each character simultaneously carries the pronunciation, the meaning, and the symbol (Woo, 2019). Most Chinese characters are monosyllabic and stand as free morphemes which can be used as independent words or in compound words (Hu, 1981; Shao, 2001), whereas the majority of modern Chinese words are making up of two characters. Nearly $96 \%$ of the Chinese characters are composed of more than one radical, and each character formed from clusters of strokes (Su, 2001). For compound characters, the majority are ideo-phonetic compounds (Cheung, McBride-Chang, \& Chow, 2006; Kang, 1993; Li \& Kang, 1993) composing of a semantic radical cueing the meaning and a phonetic radical indicating the pronunciation. Regarding the Chinese orthographic system, there are three levels, the first level is the stroke, such as "—”; the next level is the componential chunk, such as “f ”; and the third level is the full character, such as “打” (Perfetti \& Tan, 1999).

$\mathrm{Li}$ (2014) considered the recognition of Chinese characters to be the very foundation of early Chinese language acquisition, and a steppingstone towards developing the ability to read and write. In learning Chinese as a second language, morphological awareness and lexical tones are vital to the listening, speaking, and reading aspects of language development of NCS students. Morphological awareness is the ability to notice "the morphemic structure of words and their ability to reflect on and manipulate that structure" (Carlisle, 1994, p.194) and lexical tone refers to the pitch of syllables. There are nine lexical tones in Cantonese and every syllable contains one lexical tone (Tse, 2014). On top of that, phonological awareness, radical awareness, orthographic awareness, and syntactic skills are also crucial. Give the structural characteristics of Chinese characters, both orthographic skills including radical awareness and structural knowledge were found to be important for beginning native and non-native learners of Chinese (e.g. Loh, Liao, \& Leung, 2018; Shen \& Ke, 2007).

\section{THE PRESENT STUDY}

NCS children encounter a considerable number of learning difficulties, they not only have a higher school drop-out rate compared to the Chinese students, their parents also have difficulties in helping them to learn Chinese (The Zubin Foundation, 2017). Once the young children have lagged behind in their language abilities, it is difficult for them to catch up. According to the Matthew Effect introduced by Stanovich (1986), children's capacity for learning is restricted by their reading ability, thus causing a vicious cycle. The gap between children with slower academic progress and those with faster progress widens as they progress through school, hence educators must diagnose NCS children's literacy difficulties and provide them with timely and effective support measures. In order to tackle the problem at source, a five-year project "C-for-Chinese@JC" was launched in 2016 with the aim of developing the fundamental 
Chinese language proficiency of NCS kindergarten students in order to ensure a better transition into primary education and early integration within Hong Kong society.

Aim of Study

This longitudinal research study aims to analyze the Chinese language development of Hong Kong NCS kindergarteners in three aspects, namely listening, speaking, and reading. To have a better understanding of their Chinese language development, descriptions at different grades of their Chinese language abilities in the three domains were identified. Insights generated regarding the specific needs of NCS children in Chinese language learning in terms of future policy formulation will also be discussed.

\section{Methodology}

\section{A. Participants}

The present data were drawn from a five-year project. This study involved 88 ethnic minority preschoolers (50 boys and 38 girls) from six kindergartens in the 2016-17 cohort (i.e., the first year of the project). Their mean age was 40 months ( $\mathrm{SD}=4.02$ months) in the beginning of the study and most of them were Nepalese $(42 \%)$ and Pakistani $(30.7 \%)$. The distribution of participants' ethnicity can be seen at Table 1.

TABLE 1. ETHNICITY OF PARTICIPANTS

\begin{tabular}{|c|c|c|}
\hline Ethnicity & $\mathbf{N}$ & Percentage (\%) \\
\hline Pakistani & 27 & 30.7 \\
\hline Indian & 16 & 18.2 \\
\hline Nepalese & 37 & 42.0 \\
\hline Filipino & 3 & 3.4 \\
\hline Vietnamese & 2 & 2.3 \\
\hline Others & 3 & 3.4 \\
\hline Total & 88 & 100 \\
\hline
\end{tabular}

\section{B. Data Collection}

The same cohort of 88 students were traced for three consecutive years and data were collected in four time points: (i) in the beginning of K1 in October 2016 (K1 Pre-test); (ii) at the end of K1 in June 2017 (K1 Post-test); (iii) at the end of K2 in June 2018 (K2 Post-test); (iv) at the end of K3 in June 2019 (K3 Post-test). All participants attended all assessments in the four time points. Every assessment was conducted on a one-to-one basis by a trained kindergarten teacher at the participants' kindergartens and each assessment lasted for 45 minutes. School and parent consents had been obtained before data collection.

\section{Instrument}

The Chinese Language Learning Progression Framework for Non-Chinese Speaking Children in Kindergartens in Hong Kong (LPF) (Lam, Hui, \& Cheung, 2018) was adopted to test the Chinese language proficiency of NCS students in the four time points. LPF was developed as a tool to measure NCS preschoolers' basic competence in Chinese with the financial support from the Hong Kong Education Bureau (Quality Education Fund, 2017). Each assessment contains two papers. Paper I assesses students' listening and speaking abilities. For listening domain, NCS students' understanding of verbal commands, questions, descriptive content, and informational content are evaluated; and for the speaking domain, students' verbal abilities in answering questions, describing personal experience, providing information, making enquiries or requests, and expressing views or feelings are tested. Paper II assesses students' reading ability - how well they can recognize Chinese characters or components, read aloud text, retell text, link text with daily life experience, and understand of common daily used words. Students then obtain marks for different tests. The scores range from 0 to12 for the listening test; from 0 to15 for speaking and reading tests. Zero mark represents students' giving no response during the test. A sample test was attached in the Appendix.

Taking the assessment results of 279 students in LPF in the second year of the project, the project team has developed five levels in each testing domain to reflect preschoolers' standards in Chinese language proficiency. The higher the level, the better their Chinese language abilities.

TABLE 2.

LeVel INDiCATor Of Chinese LANGUAGe LEARning Progression Framework

\begin{tabular}{llll}
\hline \multirow{2}{*}{ Level } & Range of Score & & \\
\cline { 2 - 4 } & Listening domain & Speaking domain & Reading domain \\
\hline 0 & 0 & 0 & 0 \\
1 & $1-3$ & $1-4$ & $1-4$ \\
2 & $4-6$ & $5-8$ & $5-8$ \\
3 & $7-9$ & $9-12$ & $9-12$ \\
$3^{*}$ & $10-12$ & $13-15$ & $13-15$ \\
\hline
\end{tabular}

D. Analysis 
SPSS statistical methods were used to carry out simple quantitative analyses; comprising Cohen's d (1988) effect size calculator used for the calculation of value-addedness between the pre-tests and post-tests and two-way repeated measures ANOVA in order to evaluate the Chinese language ability of participants in the three areas of listening, speaking, and reading. During the assessment test, the assessor rated the students' performance on site and video-taped the process. In order to give readers about the information of the actual language performance of NCS students, detailed descriptions of students' Chinese language abilities from K1 to K3 will be presented apart from descriptive statistics of the results. The descriptions were episodes drawn from the assessment videos.

\section{RESULTS}

\section{A. Overall Chinese Performance of NCS Preschoolers}

A two-way repeated measures ANOVA was conducted to investigate the interaction effect of four time points and the three domains (listening, speaking, and reading) on LPF sub-scores of NCS students. Mauchly's test indicated that the assumption of sphericity had been violated for the interaction, $\chi 2(20)=129.78, p<0.001$. Therefore, a GreenhouseGeisser correction was applied.

Results showed that there was a significant interaction effect, $\mathrm{F}(3.92,340.79)=17.65$. Further tests revealed that at the $\mathrm{K} 1$ Pre-test, the listening score $(\mathrm{M}=2.36, \mathrm{SD}=2.16)$ was significantly higher than the speaking score $(\mathrm{M}=0.79$, $\mathrm{SD}=1.37, \mathrm{p}<0.001)$, but did not differ to the reading score $(\mathrm{M}=2.52, \mathrm{SD}=2.94, \mathrm{p}=1.00)$. The reading score was also significantly higher than the speaking score $(\mathrm{p}<0.001)$.

At K1 Post-test, the listening score $(\mathrm{M}=3.09, \mathrm{SD}=2.33)$ was significantly higher than the speaking score $(\mathrm{M}=0.87$, $\mathrm{SD}=1.67, \mathrm{p}<0.001)$ and lower than the reading score $(\mathrm{M}=4.35, \mathrm{SD}=3.36, \mathrm{p}=0.014)$. The reading score was significantly higher than the speaking score $(\mathrm{p}<0.001)$. At $\mathrm{K} 2$ Post-test, the listening score $(\mathrm{M}=4.86, \mathrm{SD}=2.90)$ was significantly higher than the speaking score $(\mathrm{M}=2.68, \mathrm{SD}=2.47, \mathrm{p}<0.001)$ and the reading score $(\mathrm{M}=3.82, \mathrm{SD}=1.93$, $\mathrm{p}=0.001)$. The reading score was also significantly higher than the speaking score $(\mathrm{p}<0.001)$. At K3 Post-test, the listening score $(M=6.98, S D=3.37)$ was significantly higher than the speaking score $(M=5.30, S D=3.79, p<0.001)$ and the reading score $(\mathrm{M}=5.19, \mathrm{SD}=2.77, \mathrm{p}<0.001)$. The reading score was no different to the speaking score $(\mathrm{p}=$ $1.00)$.

Figure 1 shows that listening scores were consistently higher than that of speaking over the four time-points, with a similar rate of improvement. Reading scores, on the other hand, showed a slower rate of improvement, starting close to the listening scores at K1 Pre-test, but ending close to the speaking scores afterwards.

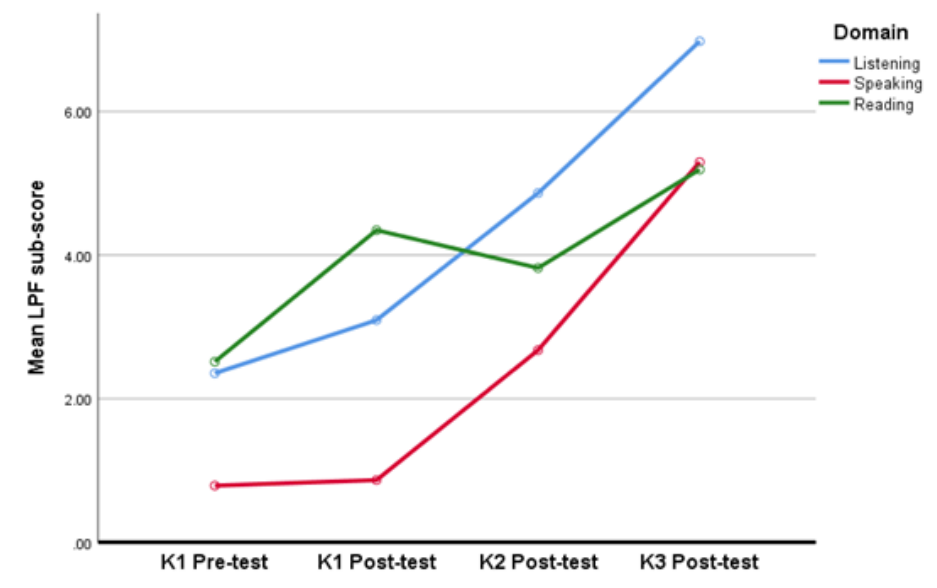

Figure 1. Participants’ LPF Mean Score in Different Domains over Time.

As drawn from the records of the assessment tests, it was found that at the end of their K1, the participating NCS preschoolers were capable of performing various listening tasks with the assistance of an adult and could also recognize some commonly-used Chinese character components and characters, even though they could not speak to the assessor in Cantonese. Towards the end of lower class (K2), the participating preschoolers were generally capable of finishing simple listening tasks independently and without hints, and could deliver some Chinese words, including nouns, verbs or adjectives, when answering simple questions. In the reading domain, they began to get acquainted with basic Chinese character components and content and could read some text or print aloud in Cantonese with limited understanding of the content. Upon completion of kindergarten education, the K3 preschoolers were able to follow verbal instructions and process complicated tasks independently. Occasionally, they were willing to deliver words, phrases, or sentences in Cantonese in order to express themselves. Ultimately, their reading ability was further improved through the combined training they received at school, with their family and in society at large. The participating NCS children were able to read aloud some text and environmental prints in Cantonese and deliver short sentences to retell part of a story without 
the assistance of an adult. By developing their reading ability, they became capable of understanding the text, grasping the storyline and connecting the reading with their own real-life experiences.

As a summary, NCS preschoolers progressed their Chinese language proficiency over time in terms of their listening, speaking, and reading abilities. Among the three, their speaking abilities seemed to be the worse at the beginning of their kindergarten schooling, followed by reading, and the best was their listening abilities. Their speaking abilities progressed significantly from K1 Post-test to K2 Post-test and from K2 Post-test to K3 Post-test with a large effect size. Their listening abilities progressed in a similar pattern, but the effect size was only medium. For the reading domain, while a significant increase with medium effect size was found from K1 Pre-test to K1 Post-test, there was a decrease in mean scores in K2 Post-test and their reading abilities advanced again in K3 Post-test. The summary of results of NCS students in different domains can be found in Table 3.

TABLE 3.

MEAN SCORES IN LPF OF NCS STUDENTS IN DIFFERENT DOMAINS

\begin{tabular}{|c|c|c|c|c|c|}
\hline \multirow[t]{2}{*}{ Domain } & K1 Pre-test & \multicolumn{2}{|l|}{ K1 Post-test } & \multirow[t]{2}{*}{$p$} & \multirow[t]{2}{*}{ Cohen's d } \\
\hline & $\mathrm{M}$ & M & $\mathrm{MD}(\mathrm{SD})$ & & \\
\hline Listening & 2.36 & 3.09 & $0.74(2.10)$ & .001 & 0.33 \\
\hline Speaking & 0.79 & 0.87 & $0.08(0.96)$ & .455 & 0.05 \\
\hline \multirow[t]{3}{*}{ Reading } & 2.51 & 4.35 & $1.83(4.55)$ & .000 & 0.58 \\
\hline & K1 Post-test & K2 Post-test & & & \\
\hline & $\mathrm{M}$ & $\mathrm{M}$ & $\mathrm{MD}(\mathrm{SD})$ & & \\
\hline Listening & 3.09 & 4.86 & $1.77(2.94)$ & .000 & 0.67 \\
\hline Speaking & 0.87 & 2.68 & $1.81(2.05)$ & .000 & 0.86 \\
\hline \multirow[t]{3}{*}{ Reading } & 4.35 & 3.82 & $-0.53(3.70)$ & .185 & -0.19 \\
\hline & K2 Post-test & K3 Post-test & & & \\
\hline & $\mathrm{M}$ & $\mathrm{M}$ & MD (SD) & & \\
\hline Listening & 4.86 & 6.98 & $2.11(3.21)$ & .000 & 0.67 \\
\hline Speaking & 2.68 & 5.30 & $2.62(3.11)$ & .000 & 0.82 \\
\hline Reading & 3.82 & 5.19 & $1.37(2.70)$ & .000 & 0.57 \\
\hline
\end{tabular}

\section{B. Performance in Listening}

As seen in the level distribution on listening domain (Table 4), there was an increasing proportion of participants attaining higher levels from K1 Pre-test to K3 Post-test. At K1 Pre-test, over $70 \%$ of participants fell into Level 0 and Level 1 but in K3 Post-test, only about one-fifth of students $(19.3 \%)$ were in these two levels. The percentage of students achieving Level 3 and Level $3 *$ increased from 5.6\% in K1 Pre-test to 56.8\% at K3 Post-test.

TABLE 4

LEVEL DISTRIBUTION ON LISTENING DOMAIN OF NCS STUDENTS

\begin{tabular}{lll||ll||ll||l||}
\hline & K1 Pre-test & \multicolumn{3}{l||}{} & K1 Post-test & K2 Post-test & K3 Post-test \\
\cline { 2 - 8 } & $\mathrm{N}$ & $\%$ & $\mathrm{~N}$ & $\%$ & $\mathrm{~N}$ & $\%$ & $\mathrm{~N}$ \\
\hline Level 0 & 18 & 20.5 & 14 & 15.9 & 5 & 5.7 & 2 \\
Level 1 & 45 & 51.1 & 39 & 44.3 & 25 & 28.4 & 15 \\
Level 2 & 20 & 22.7 & 30 & 34.1 & 37 & 42.0 & 2.3 \\
Level 3 & 4 & 4.5 & 3 & 3.4 & 14 & 15.9 & 27 \\
Level 3* & 1 & 1.1 & 2 & 2.3 & 7 & 8.0 & 23.0 \\
\hline
\end{tabular}

Based on the records of assessment tests, the general characteristics of Chinese listening abilities of NCS students from K1 to K3 are captured and described below. Generally speaking, NCS students experienced effective Chinese teaching and learning during their preschool years, which resulted in a large upswing in their listening proficiency.

In their K1, most NCS students had a basic understanding of simple commands, simple questions [such as grasping the names of some commonly-used objects and knowing some emotion vocabularies (e.g., happy, love)], simple descriptive content (such as comprehending the name and actions of a story's character and the storyline), and simple informational content (such as receiving different messages concerning the names, colors, and forms of an object) with the assistance of an adult (e.g. gesture, move or picture). For example, children could pick up a handkerchief and put it in a basket when being commanded (the adult had to make a gesture to put down something). When being shown a picture of a smiling girl and were asked “你覺得點呀? / nie5 gok3 dak1 dim2 aa1 / How do you feel?”, they were able to respond accordingly. When an adult told a story and showed a picture from the story and asked “個主角做咩? / go3 zyu2 gok3 zou6 me1 / What does the main character do?" and the child responded accordingly. When the assessor took out a fork, making a gesture of eating and asked “呢個係咩? / nil go3 hai6 me1 / What is it?”, the child could respond accordingly.

When moving to the end of K2, NCS students had a nearly complete understanding of simple commands (perform simple tasks) and simple questions independently and without hints. For example, they could respond to simple command in Cantonese, such as “拎個樽放入個環保袋 / ling1 go3 zeon1 fong3 jap6 go3 waan4 bou2 doi2 / Take a bottle and put it inside the Eco bag” or answered simple question in Cantonese such as “你鐘唔鐘意水果? / nei5 zung1 m4 zung1 ji3 seoi2 gwo2 / Do you like fruits?”. Moreover, they had a nearly complete understanding of simple 
descriptive / informational content with limited assistance of an adult. For example, after telling a story, the assessor asked the child “發生緊咩事? / faat3 sang1 gan2 me1 si6 / What's happening?”, the child could respond accordingly. When the assessor took out a fork, making a gesture of eating and asked “呢個係咩? / ni1 go3 hai6 me1 / What is it?” and “你點樣用佢? / nei5 dim2 joeng6 jung6 keoi5 / How do you use it?”, the child could respond accordingly.

At the end of $\mathrm{K} 3$, most NCS students had reached a satisfactory standard in listening. In addition to simple commands and questions, they now had a nearly complete understanding of complex commands and complicated questions. They were able to perform three or more commands in sequence independently; could verbalize feelings as well as the names and usages of commonly-used objects and gave reasons for their answers. For example, the assessor delivered a complex command in Cantonese, such as “拎起個郵票, 將佢痴係紅色信封, 然後將個信封封好 / ling1 hei2 go3 jau4 piu3, zoeng1 keoi5 ci1 hai2 hung4 sik1 seon3 fung1, jin4 hau6 zoeng1 go3 seon3 fung1 fung1 hou2 / pick up a stamp, stick it on the red envelop, and then seal the envelop" or the assessor took out a pencil, a bottle, and a towel and asked “邊個係水樽? / bin1 go3 hai6 seoi2 zeon1 / which one is a bottle?” and “你用佢嚟做咩? / nei5 jung6 keoi5 lai4 zou6 me1 / What do you use it for?”, the child was able to respond correctly. Moreover, students had nearly complete understanding of descriptive and informative content. They could comprehend the names and the actions of the story's character(s), and the storyline without hints as well as grasping different messages concerning the name, color, and form of an object. For example, the assessor told a story and asked “個故事講咩? / go3 gu3 si6 gong2 me1 / What's happening in the story?” and “故事結尾係點? / gu3 si6 git3 mei5 hai6 dim2 / What's the ending?”, and the child responded appropriately. Or the assessor provided information in Cantonese about the usage of a fork and asked “隻叉有咩用? / zek3 caa1 jau5 me1 jung6 / What's the function of a fork?” and the child could answer correctly.

\section{Performance in Speaking}

Table 5 shows the level distribution in the speaking domain. Nearly all students were categorized as Level 0 and Level 1 in K1 Pre-test (97.8\%) and K1 Post-test (96.6\%). Starting from K2 Post-test, their speaking performance was improving. A majority of students $(85.2 \%)$ attained Level 1 or above in K2 Post-test; and in K3 Post-test, more than a half of the participants $(52.2 \%)$ reached Level 2 or above.

TABLE 5 .

LEVEL DISTRIBUTION IN SPEAKING DOMAIN OF NCS STUDENTS

\begin{tabular}{|c|c|c|c|c|c|c|c|c|}
\hline & \multicolumn{2}{|c|}{ K1 Pre-test } & \multicolumn{2}{|c|}{ K1 Post-test } & \multicolumn{2}{|c|}{ K2 Post-test } & \multicolumn{2}{|c|}{ K3 Post-test } \\
\hline & $\mathrm{N}$ & $\%$ & $\mathrm{~N}$ & $\%$ & $\mathrm{~N}$ & $\%$ & $\mathrm{~N}$ & $\%$ \\
\hline Level 0 & 43 & 48.9 & 44 & 50.0 & 13 & 14.8 & 2 & 2.3 \\
\hline Level 1 & 43 & 48.9 & 41 & 46.6 & 55 & 62.5 & 40 & 45.5 \\
\hline Level 2 & 1 & 1.1 & 2 & 2.3 & 17 & 19.3 & 26 & 29.5 \\
\hline Level 3 & 1 & 1.1 & 0 & 0 & 3 & 3.4 & 15 & 17.0 \\
\hline Level 3* & 0 & 0 & 1 & 1.1 & 0 & 0 & 5 & 5.7 \\
\hline
\end{tabular}

From the records of assessment tests, about half of the NCS students were in the silent period of Cantonese speaking in their K1 and they were totally incapable to express verbally. Even some of them could speak a little, they only had very limited expression when answering questions, describing experiences, providing information, asking questions, making requests, or expressing views or feelings.

Toward the end of K2, the majority of the students had departed from the silent period. Most of them were able to give simple answers in relating to simple questions asking about an object or an event. For example, they were able to give answers relating to the nouns (蛋糕 / daan6 gou1 / cake), verbs (轆 /luk1 /roll) or adjectives (綠色 / luk6 sik1 / green). They could use simple words to describe experience, provide information (such as the name or usage of an object), make simple enquires or requests, such as nouns (聖誕節 / sing3 daan3 zit3 / Christmas; 小貓 / siu2 maau1 / kitten; 消防車 / siu1 fong4 ce1 / fire engine), verbs (玩 / waan2 / play; 推 / teoi1 / push) or adjectives (靚 / leng3 / beautiful; 紅色 / hung4 sik1 / red). They were also able to express views or feelings toward an event or action using words relating to nouns (媽咪 / maa1 mi4 / mommy), verbs (笑/ siu3 / smile) or adjectives (開心 / hoi1 sam1 / happy).

At a late stage of K3, students were able to use phrases or simple sentences to communicate with others. For example, they could deliver verb-object phase (食啫喱 / sik6 ze1 lei2 / eat jelly) or subject-verb-object pattern (呢個係電車 / ni1 go3 hai6 din6 ce1/This is a tram) to give simple answers to questions relating to an object and an event. They could also use verb-object phrase (見到蝴蝶 / gin3 dou3 wu4 dip2 / see a butterfly) or cause-and-effect structure (因為學校 好多哩玩, 好多功課界我哋。/ jan1 wai6 hok6 haau6 hou2 do1 je5 waan2, hou2 do1 gung1 fo3 bei2 ngo5 dei6 / It is because the school offers me a lot of toys to play with and gives me a lot of homework) to describe personal experience or narrate the experience of an event or activity. Moreover, they were able to use coordinate phase (私家車同埋巴士 /si1 gaa1 ce1 tung4 maai4 baa1 si6/ private car and bus) or subject-verb-object pattern (妹妹有裙子同公仔 / mui6 mui6 jau5 kwan4 zi2 tung4 gung1 zai2 / My sister has a dress and a doll). When making enquiries or requests, they could deliver coordinate phase (可以飲水? /ho2 ji5 jam2 seoi2 / Can drink water?) or subject-verb-object pattern (佢唔 識寫香蕉 / keoi5 ng4 sik1 se2 hoeng1 ziu1 / He doesn't know how to write “banana”) to solicit assistance from adults. 
Furthermore, students could use subject-predicate phrase (我鍾意 / ngo5 zung1 ji3 / I love) or cause-and-effect structure (好肚餓, 因為布食早餐 / hou2 tou5 ngo6, jan1 wai6 mou5 sik6 zou2 caan1 / hungry, because haven't eaten breakfast) to express views or feelings about an event / action or give reasons to feelings.

\section{Performance in Reading}

Table 6 shows the level distribution in the reading domain. Similar to that of speaking, nearly half $(45.5 \%)$ of participating students got zero mark in K1 Pre-test but no student remained in this level at K3 Post-test. Students' performance had improved by K1 Post-test with 75\% of students reached Level 1 or above. At K3 Post-test, over 60\% of students reached Level 2 or above.

TABLE 6.

LEVEL DISTRIBUTION ON READING DOMAIN OF NCS STUDENTS

\begin{tabular}{|c|c|c|c|c|c|c|c|c|}
\hline & \multicolumn{2}{|c|}{ K1 Pre-test } & \multicolumn{2}{|c|}{ K1 Post-test } & \multicolumn{2}{|c|}{ K2 Post-test } & \multicolumn{2}{|c|}{ K3 Post-test } \\
\hline & $\mathrm{N}$ & $\%$ & $\mathrm{~N}$ & $\%$ & $\mathrm{~N}$ & $\%$ & $\mathrm{~N}$ & $\%$ \\
\hline Level 0 & 40 & 45.5 & 22 & 25 & 1 & 1.1 & 0 & 0 \\
\hline Level 1 & 34 & 38.6 & 37 & 42 & 45 & 51.1 & 32 & 36.4 \\
\hline Level 2 & 9 & 10.2 & 22 & 25 & 40 & 45.5 & 40 & 45.5 \\
\hline Level 3 & 5 & 5.7 & 7 & 8 & 2 & 2.3 & 16 & 18.2 \\
\hline Level 3* & 0 & 0 & 0 & 0 & 0 & 0 & 0 & 0 \\
\hline
\end{tabular}

NCS preschoolers' reading abilities in K1 and K2 were similar. They were able to recognize two to four common Chinese character components, such as “;”, “女” or “ $f$ ”. For example, when the assessor displayed word cards for “媽媽 / maa4 maa1 / mother” and “姐姐/ ze4 ze1 / elder sister”, the child could point out the same Chinese component “女/ neoi5 / female" in each word. When given a story book that students used during the school semester, they were able to read out about one-third of the book without understanding the meaning. Moreover, when the assessor told a story, the children were able to grasp the text roughly with the assistance of an adult (e.g. picture, question), such as delivering simple words and phrases “去餐廳, 食呀 / heoi3 caan1 teng1, sik6 aa3 / Go to restaurant, eat!)” to retell part of the story. They were also able to roughly connect the text with real-life experiences and recognize some environmental prints with the assistance of an adult (e.g. picture, question), for example, the assessor showed a picture of a kid go eating ice-cream with his mum and asked “佢哋做緊咩? / keoi5 dei6 zou6 gan2 me1 / What are they doing?" or the assessor showed photos of different places and asked “呢度喺邊度? / ni1 dou6 hai2 bin1 dou6 / Where is it?", and the children could respond accordingly.

Toward the end of K3, students were able to recognize more Chinese character components (around five to six

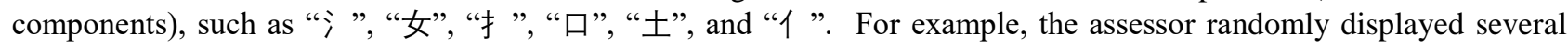
word cards and the student could match the Chinese component with their corresponding words, such as “沙灘 / saa1 taan1 / beach” to “;”; “喝水 / hot3 seoi2 / drink water” to “口 / hau2 / mouth”; “商場 / soeng1 coeng4 / shopping mall” to “土 / tou2 / ground" ... etc. When given a story book that students used during the school semester, students could read aloud in Cantonese about two-thirds of the book with limited understanding of the content; they had a sense of the people, places, and events in the storyline. For example, they could tell “他們在候診大堂等候...最後他還是喝 下了藥水 / taa1 mun4 zoi6 hau6 can2 daai6 tong4 dang2 hau6...zeoi3 hau6 taa1 waan4 si6 hot3 haa6 liu5 joek6 seoi2 / They wait in the waiting room ... Finally, he still drinks the medicine" and identify the story's theme as "consulting a doctor". When the assessor told a story, students now could retell a small part of the story independently and without hints. For example, they would say “佢病咗, 要睇醫生, 要食藥 / keoi5 beng6 zo2, jiu3 tai2 ji1 sang1, jiu3 sik6 joek6 / He's sick, needs to consult a doctor and take medicine" which was part of the storyline. Finally, they were able to connect the text with real-life experiences and recognize a few samples of environmental prints independently. For example, the assessor invited students to share their views on what they had been reading with questions such as “如果 你係佢, 你會唔會都係咁做? / jyu4 gwo2 nei5 hai6 keoi5, nei5 wui5 m4 wui5 dou1 hai6 gam2 zou6 / If you were the character, would you also do this?" and the students responded appropriately. When being displayed with word cards such as “保持安靜 / bou2 ci4 on1 zing6 / keep silence” or “商場 / soeng1 coeng4 / shopping mall”, the students could tell the meaning without hints.

\section{DISCUSSION AND CONCLUSION}

This study aims to trace the path of NCS preschoolers' development in Chinese language proficiency throughout their kindergarten years and thus create a general description of their Chinese language development. To summarize, the subjects' Chinese language development resembles the stages of second language development proposed by Tabors (2008). At K1 Pre-test, the participating NCS preschoolers were able to complete sporadic listening tasks with the assistance of an adult, but failed to complete the speaking and reading tasks (silent period). By end of K1 to end of K2, participants were in their "telegraphic and formulaic speech" stage. By K1 Post-test, the preschoolers were capable of performing various listening tasks with the assistance of an adult and could also recognize some commonly-used 
Chinese character components and characters, even though they could not speak in Cantonese. In K2 Post-test, the participants could finish simple listening tasks independently and without hints in general, and could deliver some Cantonese words, including nouns, verbs, or adjectives and could answer to simple questions. In the reading domain, they began to get acquainted with the basic Chinese character components and content and could read some text or print aloud in Cantonese with limited understanding of the content. In K3 Post-test, preschoolers were in the "productive language" stage. They were able to follow verbal instructions and process complicated tasks independently and without hints. Occasionally, they were willing to deliver words, phrases, or sentences in Cantonese in order to express themselves. Ultimately, their reading ability was further improved. They were able to read aloud some text and environmental print in Cantonese and deliver short sentences to retell part of a story without the assistance of an adult.

Results showed that NCS preschoolers progressed towards higher levels of language proficiency at K3. Their listening abilities increased steadily from K1 to K3. According to Tse, Lee, and Chan (2015), listening is the starting point of children's language learning. Children first listen (input) then speak (output), and thus, like any other language, proficiency in Chinese begins with listening followed by speaking and then reading. It would be logical to expect that preschoolers are able to understand instructions from teachers and listen attentively before participating in language activities. The Guide (Curriculum Development Council, 2017) advocates a pedagogical approach that places emphasis on the importance of catering for preschoolers' interests and improving their listening skills through various learning activities, such as singing nursery rhymes, listening to stories, and reading picture books. When preschoolers' language experiences are enriched through a variety of pleasurable activities their listening skills will flourish spontaneously.

Among the three domains of skills tested in the study, their progress in speaking Cantonese was relatively slow, with just $45.5 \%$ of participating students attaining Level 1 in the last assessment. This finding reflected the deficiency in oral learning and practicing opportunities that impacts upon NCS preschoolers' speaking skills. Taking into account the actual performance in this study, it is necessary to create for NCS preschoolers a language-rich environment, so they can immerse themselves in the local language culture and social context and have more chances to speak Cantonese. Livaccari (2012) highlights that teachers could encourage second language learners to speak spoken Chinese exclusively during those learning activities and lessons that adopt Chinese as the medium of instruction. Law, Rush, King, Westrupp, and Reilly (2018) suggested some home activities that have a positive impact on the development of early communication skills in children aged three to five years, such as parents' reading and storytelling. In his research work on Chinese language development in children exploring the effective pedagogies for learning Chinese in Hong Kong, Tse (2002) formulated specific recommendations in an integrative perceptual approach to learning Chinese characters which facilitate children to learn Chinese characters and words in a pleasurable way. Unlike first language learners, NCS preschoolers lack the parental involvement in their oral Chinese language learning. Although NCS students are deficient in home-based acquisition of Chinese, this situation can be improved through their immersion in the learning process together with their peers. The present study has demonstrated that through local kindergarten schooling, NCS students will gain valuable Chinese language experience from this early learning stage. They will greatly enrich their vocabularies, significantly improve their Chinese language competency, and thus continue to build confidence to speak Cantonese in their daily lives.

Participants' Chinese reading ability has dropped in K2 but rebounded in K3. One possible explanation for the decrease in reading ability is that students were not performing their comprehension skills but only recalling their memories from their class learning. In their early stage, NCS preschoolers learn Chinese by rote memorization and thus when they are overwhelmed by loads of new information (i.e., the Chinese language), it is impossible for them to recognize those Chinese characters which they are not familiar with. As argued by Anderson and Pearson (1984), children's prior knowledge of a given topic has far-reaching implications for the development of their reading competence, and in particular their ability to handle inferential questions (Pearson, Hansen, \& Gordon, 1979). The development of basic reading competence in Chinese is governed by factors such as the curriculum, teaching pedagogies, and textbooks; however, the focus of reading should be on the recognition of characters and writing of words. In order to ensure a smooth transition from pre-school education to primary education, the school-based curriculum will always emphasize the importance of word recognition during the K3 learning stage and implement a number of support measures with a view to enhancing children's Chinese proficiency.

The study results were based on summative assessment undertaken before participants' kindergarten graduation and, as Taras (2005) mentioned, these results can be regarded as standards and norms of their Chinese language development since the assessment collates all the evidence and constructs a reference point.

The current evidence-based descriptions can serve as benchmark indicators, offering an objective reflection of NCS preschoolers' Chinese proficiency at their kindergarten stage of schooling. Previous research on NCS students, such as the work of Heath, Bishop, Bloor, Boyle, and Fletcher (2014), has tended to focus selectively upon those children from high-risk backgrounds, such as low socio-economic status, a family history of language/literacy difficulty, and parents with low phonological awareness, would lead to poorer literacy outcomes. In contrast, by considering the integrated education system in Hong Kong, this study captures the overall performance of participants from six kindergartens and demonstrates the average proficiency in Chinese of NCS preschoolers. As a meaningful reference, local preschools might thus apply this detailed set of descriptions as a benchmark against which to clarify the standards expected at the preschool educational stage, and then amend curriculum design, learning outcomes, and assessment standards so as to 
cater for all levels of Chinese language proficiency from beginners to advanced learners. With the recent rapid development of Chinese education in non-Chinese-speaking regions, this study might provide important information for the development of Chinese language teaching materials and pedagogies, and in turn could inspire the implementation of appropriate strategies, while also ensuring that NCS preschoolers are able to develop Chinese proficiency in an effective and pleasurable way. The findings also provide the policy makers with a concrete reference standard, which can serve to inspire future practice and policymaking in early childhood education.

Though the present study tries to present the general development of NCS students' performance in Chinese language proficiency, it should be noted that the small number of sample size would affect the generalizability of results across population. As such, future studies with a larger sample size would be useful to validate the results. In all, the descriptions in different grades of the present study provide useful information for assessing and describing NCS preschoolers' proficiency in the local language. Educators could refer to the findings and use them to get a general picture of preschoolers' learning progress, and hence will eventually be able to cater for learners' differences by implementing various modifications to their teaching. The ultimate goal is to help NCS preschoolers being capable of understanding instructions from teachers and can gradually integrate into local primary schools.

\section{DisCLOSURE STATEMENT}

No potential conflict of interest was reported by the authors.

\section{APPENDIX}

Sample of LPF assessment

\begin{tabular}{|c|c|c|c|}
\hline Domain & Subsection & Sample question & Marking scheme \\
\hline \multirow[t]{2}{*}{ Listening } & $\begin{array}{l}\text { Understanding verbal } \\
\text { instruction }\end{array}$ & "Put a book into a bag". & \multirow{2}{*}{$\begin{array}{l}0=\text { unable to answer } \\
1=\text { complete with adults' assistance } \\
2=\text { complete by himself } / \text { herself }\end{array}$} \\
\hline & $\begin{array}{l}\text { Understanding verbal } \\
\text { question }\end{array}$ & $\begin{array}{l}\text { [A toy car, a ball and a building block are } \\
\text { placed before the child.] } \\
\text { "Which is a car?" }\end{array}$ & \\
\hline \multirow[t]{2}{*}{ Speaking } & Answering questions & "Do you like going to school?" & \multirow{2}{*}{$\begin{array}{l}0=\text { unable to answer } \\
1=\text { answer in words } \\
2=\text { answer in phases } \\
3=\text { answer in sentences }\end{array}$} \\
\hline & $\begin{array}{l}\text { Expressing ideas or } \\
\text { feelings }\end{array}$ & "Why do you like (XX - animal name)?" & \\
\hline Reading & $\begin{array}{l}\text { Recognizing Chinese } \\
\text { characters ad } \\
\text { components }\end{array}$ & 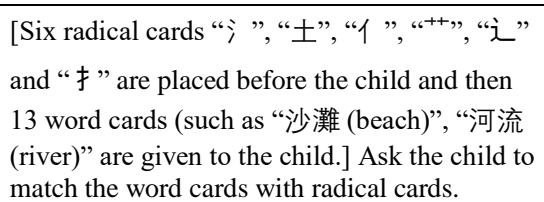 & $\begin{array}{l}0=\text { unable to answer or } 1 \text { correct answer } \\
1=2-4 \text { correct answers } \\
2=5-6 \text { correct answers }\end{array}$ \\
\hline
\end{tabular}

\section{ACKNOWLEDGMENTS}

This work and the “C-for-Chinese@ JC” project were supported by The Hong Kong Jockey Club Charities Trust.

\section{REFERENCES}

[1] Anderson, R. C., \& Pearson, P. D. (1984). A schema-theoretic view of basic processes in reading comprehension. In P. D. Pearson (Ed.), Handbook of reading research (pp. 255-291). New York: Longman.

[2] Carlisle, J. F. (1994). Morphological awareness and early reading achievement. In L. B. Feldman (Ed.), Morphological aspects of language processing (pp. 189-209). Hillsdale, N. J.: Lawrence Erlbaum Associates.

[3] Census and Statistics Department, HKSAR. (2012). 2011 Population Census Thematic Report: Ethnic Minorities. Hong Kong: Hong Kong Government Publications.

[4] Census and Statistics Department, HKSAR. (2017). 2016 Population by-census - Thematic report: Ethnic minorities. Hong Kong Census and Statistics Department. Retrieved April 30, 2020, from https://www.statistics.gov.hk/pub/B11201002016XXXXB0100.pdf.

[5] Chall, J. S. (1983). Stages of reading development. New York: McGraw-Hill Publishing Company.

[6] Cheung, H., McBride-Chang, C., \& Chow, B. W.-Y. (2006). Reading Chinese. In R. M. Joshi \& P. G. Aaron (Eds.), Handbook of orthography and literacy (pp. 421-438). Mahwah, N. J.: Lawrence Erlbaum Associates.

[7] Cohen, J. (1988). Statistical power analysis for the behavioral sciences (2nd ed.). Hillsdale, N. J.: Lawrence Earlbaum Associates.

[8] Curriculum Development Council, HKSAR. (2017). Kindergarten education curriculum guide. Hong Kong: Hong Kong Education Bureau.

[9] Education Bureau, HKSAR. (2017). Existing and planned measures on the promotion of equality for ethnic minorities. Hong Kong: Hong Kong Government Publications.

[10] Heath, S. M., Bishop, D. V. M., Bloor, K. E., Boyle, G. L., \& Fletcher, J. (2014). A spotlight on preschool: The influence of family factors on children's early literacy. PLoS ONE, 9(4): e95255.

[11] Hu, R. S. (1981). Xiandai Hanyu (zengdingben) [Modern Chinese (revised ed.)]. Shanghai: Shanghai Education Press. 
[12] Jiang, N. (2004). Semantic transfer and its implications for vocabulary teaching in a second language. The Modern Language Journal, 88(3), 416-432.

[13] Kang, J. S. (1993). Analysis of semantics of semantic-phonetic compound characters in modern Chinese. In Y. Chen (Ed.), Xiandai Hanyu yongzi xinxi fenxi [Information analysis of usage of characters in modern Chinese] (pp. 71-83). Shanghai: Shanghai Education Publisher.

[14] Lam, W. I., Hui, S. Y., \& Cheung, W. M. (2018). Chinese Language Learning Progression Framework for Non-Chinese Speaking Children in Kindergartens in Hong Kong. Hong Kong: Centre for Advancement of Chinese Language Education and Research.

[15] Law, J., Rush, R., King, T., Westrupp, E., \& Reilly, S. (2018). Early home activities and oral language skills in middle childhood: A quantile analysis. Child Development, 89(1), 295-309.

[16] Li, H. (2014). Teaching Chinese literacy in the early years: Psychology, pedagogy and practice. London: Routledge.

[17] Li, Y., \& Kang, J. S. (1993). Analysis of phonetics of semantic-phonetic compound characters in modern Chinese. In Y. Chen (Ed.), Xiandai Hanyu yongzi xinxi fenxi [Information analysis of usage of characters in modern Chinese] (pp. 84-98). Shanghai Shanghai Education Publisher.

[18] Livaccari, C. (2012). Instructional strategies: Successful approaches to immersion teaching. In Asia Society (Ed.), Chinese language learning in the early grades: A handbook of resources and best practices for Mandarin immersion (pp. 30-33). Retrieved February 28, 2020, from https://asiasociety.org/files/chinese-earlylanguage.pdf.

[19] Loh, E. K. Y., Liao, X., \& Leung, S. O. (2018). Acquisition of orthographic knowledge: Development difference among learners with Chinese as a second language (CSL). System, 74, 206-216.

[20] McBride, C. A. (2016). Is Chinese special? Four aspects of Chinese literacy acquisition that might distinguish learning Chinese from learning alphabetic orthographies. Educational Psychology Review, 28(3), 523-549.

[21] Pearson, P. D., Hansen, J., \& Gordon, C. (1979). The effect of background knowledge on young children's comprehension of explicit and implicit information. Journal of Reading Behavior, 11(3), 201-209.

[22] Perfetti, C. A., \& Tan, L. H. (1999). The constituency model of Chinese character identification. In J. Wang, A. Inhoff, \& H.-C. Chen (Eds.), Reading Chinese script: A cognitive analysis (pp. 115-134). Mahwah, N. J.: Lawrence Erlbaum Associates Publishers.

[23] Quality Education Fund, Education Bureau, HKSAR. (2017). Report on Development of Chinese Language Learning Progress Framework for non-Chinese speaking (NCS) children in kindergartens in Hong Kong. Retrieved February 5, 2020, from https://qcrc.qef.org.hk/Publish/project_information/201712/20130076FR.pdf.

[24] Shao, J. M. (2001). Xiandai Hanyu tonglun [An outline of modern Chinese]. Shanghai: Shanghai Education Press.

[25] Shen, H. H., \& Ke, C. (2007). Radical awareness and word acquisition among nonnative learners of Chinese. The Modern Language Journal, 91(1), 97-111.

[26] Shum, M. S. K., Gao, F., Tsung, L., \& Ki, W. W. (2011). South Asian students' Chinese language learning in Hong Kong: Motivations and strategies. Journal of Multilingual \& Multicultural Development, 32(3), 285-297.

[27] Stanovich, K. E. (1986). Matthew effects in reading: Some consequences of individual differences in the acquisition of literacy. Reading Research Quarterly, 21(4), 360-407.

[28] Su, P. C. (2001). Xiandai Hanzixue gangyao (zengdingben) [Modern Chinese orthography (revised ed.)]. Beijing: Peking University Press.

[29] Tabors, P. (2008). One child, two languages: A guide for early childhood educators of children learning English as a second language (2nd ed.). Baltimore, Md.: Paul H. Brookes Pub.

[30] Taras, M. (2005). Assessment-summative and formative-some theoretical reflections. British Journal of Educational Studies, 53(4), 466-478.

[31] The Zubin Foundation. (2017). Landscape study: Primary school education for non-Chinese-speaking children with special education needs in Hong Kong. Hong Kong: The Zubin Mahtani Gidumal Foundation Limited.

[32] Tse, S. K. (2002). Pedagogy: An integrative perceptual approach to learning Chinese characters. Hong Kong: Greenfield Educational Center.

[33] Tse, S. K. (2014). Oral language development of preschool children (2nd ed.). Hong Kong: Hong Kong University Press.

[34] Tse, S. K., Lee, T. N. M., \& Chan, S. P. T. (2015). Early childhood literacy: Effective Chinese language acquisition and teaching. Hong Kong: Hong Kong University Press.

[35] Verhallen, M., \& Schoonen, R. (1993). Lexical knowledge of monolingual and bilingual children. Applied Linguistics, 14(4), 344-363.

[36] Woo, P. S. (2019). The application of Stanislavski's system for the enhancement of narrative writing in Chinese as a second language for secondary school students. [Unpublished doctoral dissertation]. Hong Kong: University of Hong Kong Libraries.

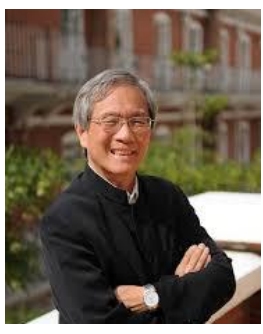

Shek Kam TSE is a professor at the Centre for Advancement of Chinese Language Education and Research (CACLER), Faculty of Education, The University of Hong Kong. His research interests include: (1) teaching Chinese as a second language; (2) the influence of interventions on early literacy development; and (3) effective Chinese language pedagogy for different stages of education. 
Cheong Yam LEUNG was an assistant lecturer at the Centre for Advancement of Chinese Language Education and Research (CACLER), Faculty of Education, The University of Hong Kong.

Pik Fong TSUI is a senior research assistant at the Centre for Advancement of Chinese Language Education and Research (CACLER), Faculty of Education, The University of Hong Kong.

Kit Yee CHAN is a lecturer at the HKU School of Professional and Continuing Education.

Mei Chi KWOK, assistant lecturer, Centre for Advancement of Chinese Language Education and Research (CACLER), Faculty of Education, The University of Hong Kong. 